\title{
Carbenoxolone Accelerates Maturation of Rat Intestine
}

\author{
JIŘÍ PÁCHA, RADKA VAGNEROVÁ, AND JANA BRYNDOVÁ \\ Institute of Physiology [J.P., J.B.], Czech Academy of Sciences, Videňská 1083, Prague 4, Czech \\ Republic; and Department of Histology and Embryology [R.V.], First Faculty of Medicine, Charles \\ University, Albertov 2, Prague 2, Czech Republic
}

\begin{abstract}
The rat undergoes profound maturational changes in the intestinal structure and function during the third week of its life. To investigate the role of peripheral glucocorticoid metabolism in this process, we studied the postnatal maturation of intestinal structure and function. The peripheral metabolism of glucocorticoids depends on enzyme $11 \beta$-hydroxysteroid dehydrogenase $(11 \beta \mathrm{HSD})$, which is responsible for the interconversion of corticosterone to 11-dehydrocorticosterone and thus for the modulation of glucocorticoid access to corticosteroid receptors. The pups were treated with carbenoxolone (CBX), an inhibitor of $11 \beta \mathrm{HSD}$, for $10 \mathrm{~d}$ during the suckling (days $8-18$ ) or weaning period (days $14-24$ or days 20-30), and we determined the parameters of intestinal growth and activities of sucrase, alkaline phosphatase, and Na,K-ATPase. The CBX treatment increased plasma concentrations of corticosterone as a result of a significant reduction of peripheral degradation of corticosterone catalyzed by $11 \beta \mathrm{HSD}$. This also stimulated intestinal growth without changing somatic growth. The mucosal cell mass was signifi-
\end{abstract}

ABSTRACT

cantly higher in CBX-treated suckling rats, whereas the effect of this treatment was less obvious in weanling animals. CBX increased the crypt depth and villus height in 18- and 24-d-old pups but not in 30-d-old animals. The small intestinal activities of sucrase, alkaline phosphatase, and Na,K-ATPase were not influenced by CBX. In contrast, colonic Na,K-ATPase was stimulated by $\mathrm{CBX}$. We conclude that the administration of $\mathrm{CBX}$ results in acceleration of intestinal growth and structural maturation without any influence on the developmental pattern of brush-border hydrolases. The results indicate an important role of peripheral glucocorticoid metabolism in the regulation of intestinal growth during early postnatal life. (Pediatr Res 53: 808813, 2003)

Abbreviations
CTR, carbenoxolone
11 $\boldsymbol{\beta H}$, controls

The concentration of glucocorticoids in the plasma plays an important physiologic role in the promotion of normal ontogeny of the human embryo in utero and of rodents during weaning. The rise of plasma glucocorticoids is associated with an accelerated maturation of various tissues (1). The local action of glucocorticoids in target tissues can be modified by changes in peripheral glucocorticoid metabolism. This metabolism depends on the enzyme $11 \beta$-hydroxysteroid dehydrogenase ( $11 \beta \mathrm{HSD})$, which has been recognized to play a key role in regulating the access of glucocorticoids to corticosteroid receptors. Two isoforms of $11 \beta \mathrm{HSD}$ with different properties and tissue distribution have been described. Type $211 \beta \mathrm{HSD}$ is a high-affinity NAD-dependent isozyme that catalyzes the conversion of cortisol and corticosterone to cortisone and

Received September 24, 2001; accepted July 1, 2002.

Correspondence: Jiři Pácha, Institute of Physiology, Czech Academy of Sciences, Vídeňská 1083, 14220 Prague 4-Krč, Czech Republic; e-mail: pacha@biomed.cas.cz

The work was supported by the Grant Agency of the Czech Republic (grant \#306/99/ 0210 and $\# 305 / 01 / 0281$ ).

DOI: 10.1203/01.PDR.0000058923.08017.6F 11-dehydrocorticosterone, respectively, and thus decreases the local concentration of active glucocorticoids and prevents their binding to mineralocorticoid receptors. In contrast, type 1 $11 \beta \mathrm{HSD}$ is a NADP(H)-dependent isoform that exhibits bidirectional activity in vitro but seems to favor 11-reductase activity in intact cells. Whereas type 2 has been predominantly found in the kidney, colonic epithelium, and placenta, type 1 is the predominant type in the liver, fibroblasts, and cells of lamina propria (2).

It has recently been shown that $11 \beta$-dehydrogenase activity is already present in the immature intestine (3) and that inhibition of this enzyme increases the binding of glucocorticoids to both mineralocorticoid and glucocorticoid receptors of enterocytes (4). Thus, the relative abundance of $11 \beta \mathrm{HSD} 1$ or $11 \beta$ HSD2 in certain tissues could enhance or inhibit the effect of glucocorticoids during development. It is widely known that intestinal maturation in laboratory rodents occurs during weaning and that glucocorticoids belong to the most potent regulators in the developing intestine studied so far $(1,5)$. At the time of weaning, the intestinal epithelium undergoes marked mor- 
phologic and biochemical changes that involve both growth and differentiation. With regard to growth, there is a shortening of the cell cycle and enhanced crypt mitotic activity and cell migration rate that are closely correlated with the increase of villus height and crypt depth (6). These changes in crypt-villus kinetics ultimately leading to the adult steady-state seem to be under the influence of glucocorticoids (7-9). With regard to cell differentiation, weaning is characterized by phenotypic changes in enterocytes that include developmental changes in the activity of various enzymes influenced by the hormonal milieu, including glucocorticoids $(1,5)$. For example, glucocorticoids have been shown to affect the developmental patterns of sucrase $(10,11)$, alkaline phosphatase (12), and $\mathrm{Na}, \mathrm{K}-\mathrm{ATP}$ ase (13-15).

The studies mentioned above support the notion that peripheral metabolism of glucocorticoids might influence intestinal maturation. To investigate this, we examined whether inhibition of peripheral glucocorticoid metabolism via inhibition of $11 \beta \mathrm{HSD}$ accelerates or retards the developmental pattern of various glucocorticoid-dependent variables (sucrase, alkaline phosphatase, and Na,K-ATPase activities; intestinal growth; villus height; and crypt depth). The peripheral metabolism of glucocorticoids was blocked by carbenoxolone (CBX), a potent inhibitor of both isoforms of $11 \beta \mathrm{HSD}(2,16-18)$.

\section{METHODS}

Animals. Wistar rats were bred and maintained in an airconditioned room at $21^{\circ} \mathrm{C}$ on a 12:12-h light-dark cycle. Standard rat diet and water were provided ad libitum throughout the experiment. The day of birth was designated as day 0 , and approximately $24 \mathrm{~h}$ after birth the litter size was reduced to eight pups that remained with their dam for the remainder of the experiments. The rats received either i.p. injections of CBX (60 $\mathrm{mg} \cdot \mathrm{kg}^{-1} \cdot \mathrm{d}^{-1}$, CBX groups) or vehicle [control (CTRL) groups]. CBX was dissolved in absolute ethanol and then diluted $1: 9$ in $0.9 \% \mathrm{NaCl}$ for daily s.c. injection. The dose 60 $\mathrm{mg} \cdot \mathrm{kg}^{-1} \cdot \mathrm{d}^{-1}$ CBX was used because administration of a similar dose reduced $11 \beta \mathrm{HSD}$ activity in the kidneys, colon, and liver (16). For determining the role of $11 \beta \mathrm{HSD}$ inhibition during suckling and weaning periods, CBX was administered daily in three series of experiments starting on postnatal days 8,14 , or 20 and lasting $10 \mathrm{~d}$. The animals were killed by decapitation $24 \mathrm{~h}$ after the end of treatment. Blood was collected and centrifuged and serum was stored $\left(-20^{\circ} \mathrm{C}\right)$ until assayed for corticosterone using RIA (ICN Biomedicals, Costa Mesa, CA, U.S.A.). The entire small intestine and colon were removed immediately after blood collection and flushed with ice-cold $150 \mathrm{mM} \mathrm{NaCl}$. The length of the intestine was measured under gentle traction then weighed, and the small intestine was separated into the jejunum and ileum. The jejunum was defined as the proximal third of the segment distal to the ligament of Treitz, and the ileum was defined as the distal third of that segment. For measurement of enzyme activities, protein, and DNA, the mucosa was scraped with a glass microscope slide. $11 \beta \mathrm{HSD}$ activity was investigated in tissue slices of kidney and liver. All experiments were approved by the Institutional Review Board.
Assay of sucrase, alkaline phosphatase, Na,K-ATPase, $D N A$, and protein. Enzyme activities were measured in $10 \%$ mucosa homogenates prepared in a Teflon homogenizer. Sucrase activity was measured according to the method of Henning and Guerin (19) using sucrose as a substrate. Glucose liberated from sucrose was quantified by a glucose oxidase reagent. Alkaline phosphatase activity was determined by the method of Murer et al. (20) using p-nitrophenol phosphate as substrate, and $\mathrm{p}$-nitrophenol was measured at alkaline $\mathrm{pH}$. The activity of $\mathrm{Na}, \mathrm{K}$-ATPase was measured as the ouabainsensitive release of inorganic phosphate from ATP as has been described previously (21). Enzyme activities were calculated as micromoles of reaction product (glucose, p-nitrophenol, phosphate) per milligram of mucosal protein per hour. Protein and DNA were determined by the method of Bradford (22) and Giles and Myers (23), respectively.

Measurement of intestinal morphology. Intestinal sections for morphometry were harvested immediately after the intestine was weighed, with the apical mucosal surface pinned onto corks face up and fixed in $10 \%$ buffered formalin. After fixation, each tissue sample was cut into two pieces and embedded in EPON 812. Vertically oriented full-thickness sections were cut from two different regions of each tissue sample and stained with toluidine blue. The crypt depth and villus height (including the thickness of the epithelium at the crypt base and villus apex) were quantified in one animal from 23 to 30 crypt-villus columns in the jejunum or ileum and 30 crypts in the colon from six sections originating from two different regions of each segment using a Zeiss microscope equipped with a micrometer. Only complete longitudinal sections of villi and unbranched crypts that showed, in continuity, the bottom and lumen of the crypt, the continuous crypt-villus junction, and the tip of the villus were evaluated. The axial height of the villus was defined as the length from the tip to the intervillus region including the thickness of the epithelium at the villus apex. Crypt length was obtained by measuring the distance from the intervillus region (colonic surface) to the crypt base including the thickness of the epithelium on both sides. Analysis of the morphometric data were performed in a blind manner to prevent observer bias.

Assay of $11 \beta H S D$ activity. Liver and kidney slices were cut with a razor blade into small strips and rinsed in ice-cold 150 $\mathrm{mM}$ saline. The conversion of corticosterone to 11dehydrocorticosterone and vice vera was measured $10 \mathrm{~h}$ after the last administration of CBX as reported by us previously (3). Briefly, incubation of the tissue (200-250 mg of wet weight) was carried out in sealed vessels containing $10 \mathrm{~mL}$ of oxygenated incubation solution and corticosterone $(1.45 \mu \mathrm{M})$ for 45 min (liver) or $75 \mathrm{~min}$ (kidney) at $37^{\circ} \mathrm{C}$. With the use of this substrate concentration, the conversion was linearly proportional to the time of incubation. The internal standard of deoxycorticosterone (final concentration $1.5 \mu \mathrm{M}$ ) was added at the end of the incubation, and the vessels were placed on ice. After centrifugation for $10 \mathrm{~min}$ at $3000 \times \mathrm{g}$, the supernatant was loaded onto a $\mathrm{C}_{18}$ reversed-phase Sep-Pak cartridge (Waters, Milford, MA) and steroids were extracted by methanol, evaporated to dryness under nitrogen, and stored at $-20^{\circ} \mathrm{C}$. The samples were analyzed using HPLC, and the results were 
expressed in nanograms of 11-dehydrocorticosterone or corticosterone per milligram of dry weight per hour.

Statistical analysis. The data are presented as the means (SD). The approximate normality of the original data and the ratio variables gut weight/body weight, gut length/body weight, and gut weight/gut length and the possible effect of error progression of ratio variables were checked out. The differences between means were tested using the unpaired $t$ test with the value $p<0.05$ considered as significant.

\section{RESULTS}

Intestinal growth in CBX-treated pups. As indicated in Table 1, CBX influenced the growth of both suckling and weanling intestines, even though this effect was more obvious during the suckling period. Total body weight was similar in both control and CBX-treated rats. Application of CBX during the suckling period increased both the weight and the length of the small intestine, but this effect disappeared when CBX was administered during the weaning period. The increase in intestinal weight was predominantly the result of the longitudinal growth because relative weight of the intestine expressed per unit of intestinal length did not differ in control and CBX-treated pups. The growth effect of CBX did not follow the same pattern along the small intestine. When expressed per unit of body weight, CBX increased gut weight in the proximal [CTRL: $1.05 \%(0.10 \%)$; CBX: $1.22 \%$ $(0.14 \%) ; p<0.01]$ and middle third of the small intestine [CTRL: $0.79 \%(0.17 \%)$; CBX: $0.91 \%(0.11 \%) ; p<0.05]$ but not in the distal third. In contrast to sucklings, the administration of CBX to weanlings did not influence the measured parameters of the small intestine with one exception (Table 1). The effect of CBX on colonic growth was similar during both the suckling and the weaning periods, and the treatment increased absolute and relative weight including an increase of weight per unit length of the colon.

Changes in intestinal mucosa during CBX treatment. The amount of proteins per unit length of the intestine was significantly different in CBX-treated and control animals (Table 2). In suckling rats, $\mathrm{CBX}$ increased the protein and DNA content in both the colon and the small intestine, whereas in weanling rats, this effect was more marked in the colon. The ratio of protein/DNA decreased during weaning, but this decrease was blocked in the colonic mucosa by CBX administration. The height of jejunal and ileal villi increased between days 18 and 30 , and this developmental increase was accelerated by CBX

Table 1. Body weight and intestinal growth in control and CBX treated rats

\begin{tabular}{|c|c|c|c|c|}
\hline Parameter & \multicolumn{2}{|c|}{ Small intestine } & \multicolumn{2}{|c|}{ Colon } \\
\hline \multicolumn{5}{|l|}{$\mathrm{B}_{\mathrm{W}}(\mathrm{g})$} \\
\hline CTRL & \multicolumn{4}{|c|}{ Day 24: $49.3(2.5)(n=8)$} \\
\hline \multirow{2}{*}{$\mathrm{CBX}$} & \multicolumn{4}{|c|}{ Day 18: $43.0(5.9)(n=18)$} \\
\hline & \multicolumn{4}{|c|}{ Day 24: $48.3(3.6)(n=9)$} \\
\hline $\mathrm{CBX}$ & $1.23(0.17)^{* *}$ & $2.24(0.16)$ & $0.23(0.04)^{*}$ & $0.43(0.05)^{* *}$ \\
\hline \multicolumn{5}{|l|}{$\mathrm{G}_{\mathrm{L}}(\mathrm{cm})$} \\
\hline CTRL & $53.9(5.4)$ & $71.2(4.0)$ & $7.0 \quad(0.4)$ & $11.1(0.7)$ \\
\hline CBX & $59.7(4.2)^{* *}$ & $70.1 \quad(3.4)$ & $7.0(0.4)$ & $11.7(0.5)$ \\
\hline \multicolumn{5}{|l|}{$\mathrm{G}_{\mathrm{W}} / \mathrm{B}_{\mathrm{W}}(\%)$} \\
\hline CTRL & $2.53(0.30)$ & $4.40(0.31)$ & $0.49(0.08)$ & $0.70(0.08)$ \\
\hline \multicolumn{5}{|l|}{$\mathrm{G}_{\mathrm{W}} / \mathrm{G}_{\mathrm{L}}(\mathrm{mg} / \mathrm{cm})$} \\
\hline CTRL & $20.19(2.48)$ & $30.4 \quad(2.12)$ & $29.9(4.6)$ & $31.2(4.0)$ \\
\hline $\mathrm{CBX}$ & $20.64(2.67)$ & $31.4(1.51)$ & $32.9(4.2)^{*}$ & $36.4(3.0)^{*}$ \\
\hline
\end{tabular}

Values are means (SD); numbers of animals are given in parentheses. CTRL, control pups received only vehicle for $10 \mathrm{~d}$ before being killed; CBX, carbenoxolone-treated pups that were given i.p. injections of CBX in a dose $60 \mathrm{mg} \cdot \mathrm{kg}^{-1} \cdot \mathrm{d}^{-1}$ for $10 \mathrm{~d}$. * $p<0.05$; ** $p<0.01$ as compared with the controls. $B_{W}$, body weight; $G_{w}$, gut weight; $G_{L}$, gut length.

Table 2. Effect of $C B X$ on intestinal mucosa

\begin{tabular}{|c|c|c|c|c|c|}
\hline \multirow[b]{2}{*}{ Parameter } & & \multicolumn{2}{|c|}{ Small intestine } & \multicolumn{2}{|c|}{ Colon } \\
\hline & & Day 18 & Day 24 & Day 18 & Day 24 \\
\hline Mucosal protein $(\mathrm{mg} / \mathrm{cm})$ & CTRL & $0.36(0.07)$ & $1.45(0.06)$ & $0.44(0.02)$ & $0.35(0.02)$ \\
\hline \multirow[t]{2}{*}{ Mucosal DNA $(\mu \mathrm{g} / \mathrm{cm})$} & CTRL & $7.1 \quad(2.0)$ & $43.2(5.0)$ & $12.1(1.0)$ & $15.1(4.0)$ \\
\hline & $\mathrm{CBX}$ & $11.2(3.9)^{*}$ & $46.3(6.1)$ & $18.4(4.9)^{*}$ & $17.3(2.9)$ \\
\hline \multirow[t]{2}{*}{ Protein/DNA } & CTRL & $53.2(4.7)$ & $35.2(3.5)$ & $35.5 \quad(3.5)$ & $25.5(6.1)$ \\
\hline & $\mathrm{CBX}$ & $53.0 \quad(4.0)$ & $32.2(4.0)$ & $32.9(4.7)$ & $37.6(7.3)^{* *}$ \\
\hline
\end{tabular}

Values are means (SD), seven rats in each group. For further details, see Table $1 .{ }^{*} p<0.05 ; * p<0.01$ as compared with controls. 
(Fig. 1). The effect of CBX was significant in the jejunum and ileum of suckling and weanling rats but disappeared in 30-dold animals. The developmental increase of the depth of jejunal, ileal, and colonic crypts was also accelerated by CBX in

Jejunum

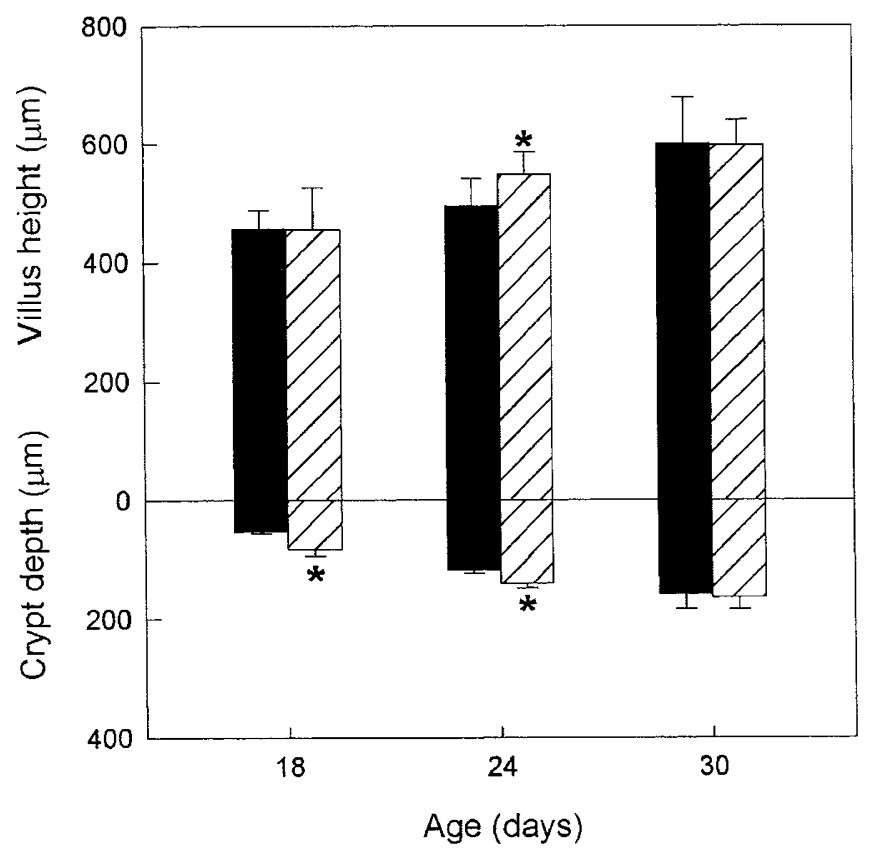

lleum

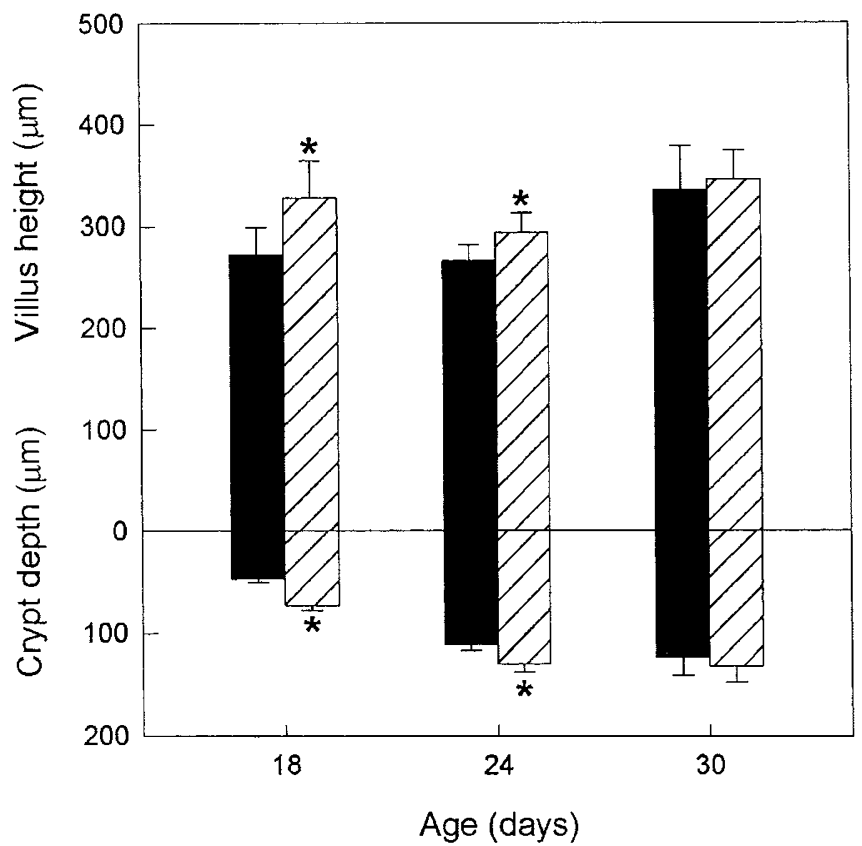

Figure 1. Effect of CBX on villus height and crypt depth in jejunum and ileum of suckling and weanling rats. The rats were treated with CBX (60 $\mathrm{mg} \cdot \mathrm{kg}^{-1} \cdot \mathrm{d}^{-1}$; hatched bars) or vehicle (CTRL; filled bars) for $10 \mathrm{~d}$ before measurements. Results are means (SD) of seven animals. ${ }^{*} p<0.05$ between control and CBX-treated animals. suckling and weaning period but disappeared after weaning (Figs. 1 and 2).

Maturational expression of sucrase, alkaline phosphatase, and Na,K-ATPase. Mucosal maturation was further assessed

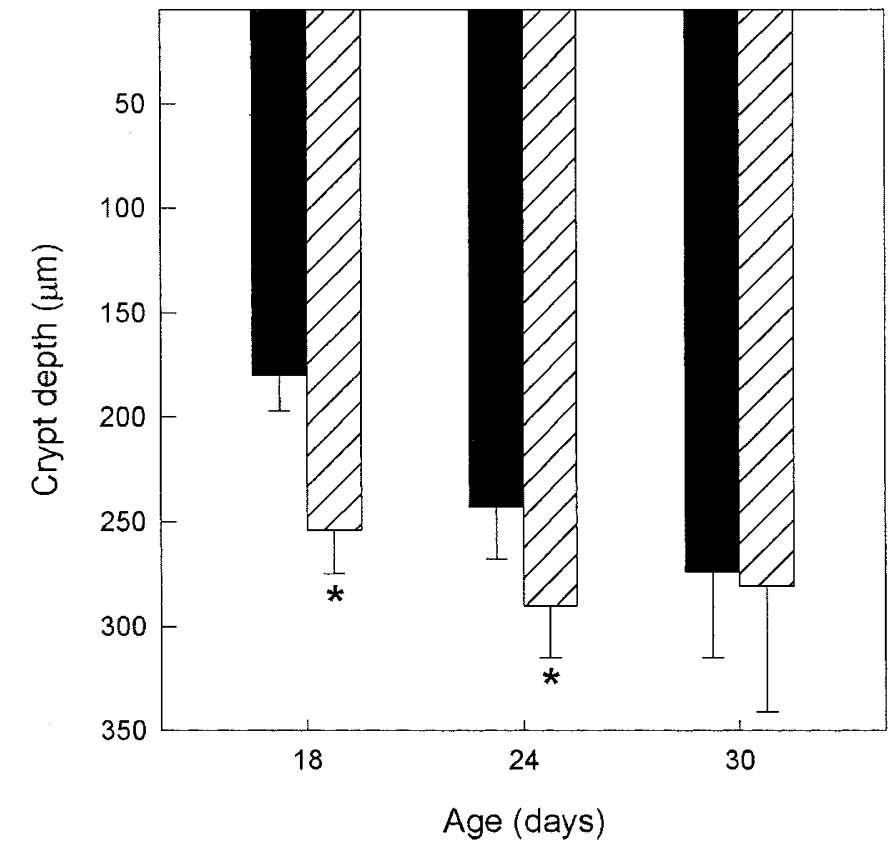

Figure 2. Effect of CBX on crypt depth in colon of suckling and weanling rats. The rats were treated with CBX $\left(60 \mathrm{mg} \cdot \mathrm{kg}^{-1} \cdot \mathrm{d}^{-1}\right.$; hatched bars $)$ or vehicle (CTRL, filled bars) for $10 \mathrm{~d}$ before measurements. Results are means (SD) of seven animals. ${ }^{*} p<0.01$ between control and CBX-treated animals.

Table 3. Effect of $C B X$ on intestinal enzymes

\begin{tabular}{clrr}
\hline & & Day 18 & Day 24 \\
\hline Alkaline phosphatase & & & \\
Jejunum & CTRL & $115.2(56.1)$ & $135.2(31.3)$ \\
& CBX & $106.0(45.5)$ & $147.1(35.7)$ \\
Ileum & CTRL & $19.0(7.5)$ & $13.1(5.4)$ \\
& CBX & $13.4(6.9)$ & $15.3(5.0)$ \\
Colon & CTRL & $9.6(6.3)$ & $3.6(1.8)$ \\
& CBX & $13.4(4.7)$ & $3.8(1.6)$ \\
Na,K-ATPase & & & \\
Jejunum & CTRL & $6.4(3.2)$ & $8.5(4.7)$ \\
& CBX & $7.0(4.1)$ & $9.1(4.4)$ \\
Ileum & CTRL & $6.9(2.8)$ & $12.8(7.2)$ \\
Colon & CBX & $8.8(4.3)$ & $9.3(6.3)$ \\
& CTRL & $8.1(2.2)$ & $10.6(2.8)$ \\
Sucrase & CBX & $12.1(4.1)^{*}$ & $15.9(5.3)^{*}$ \\
Jejunum & & & \\
Ileum & CTRL & $2.17(0.98)$ & $5.8(2.46)$ \\
& CBX & $1.98(0.92)$ & $6.6(1.96)$ \\
& CTRL & $1.63(0.75)$ & $2.4(1.07)$ \\
& CBX & $1.69(0.61)$ & $2.5(0.91)$
\end{tabular}

Values are means (SD); $10-12$ rats in each group. Alkaline phosphatase activity is expressed in micromoles of p-nitrophenol, Na,K-ATPase activity is expressed in micromoles of phosphate, and sucrase activity is expressed in micromoles of glucose per hour and milligram protein. CBX, carbenoxolonetreated animals that were given i.p. injections of carbenoxolone in a dose 60 $\mathrm{mg} \cdot \mathrm{kg}^{-1} \cdot \mathrm{d}^{-1}$ for $10 \mathrm{~d}$ before being killed; CTRL, control animals that were given vehicle only. ${ }^{*} p<0.05$; as compared with the controls. 
Table 4. Effect of CBX on $11 \beta H S D$ activity in the liver and kidney

\begin{tabular}{|c|c|c|c|}
\hline & Kidney & \multicolumn{2}{|c|}{ Liver } \\
\hline & $\mathrm{B} \rightarrow \mathrm{A}$ & $\mathrm{A} \rightarrow \mathrm{B}$ & $\mathrm{B} \rightarrow \mathrm{A}$ \\
\hline Controls & $42.3(8.1)(n=8)$ & $47.5(15.7)(n=14)$ & $21.4(7.1)(n=6)$ \\
\hline CBX-treated & $28.2(6.1)(n=8)^{* *}$ & $16.2(8.9)(n=14)^{* *}$ & $4.7(1.7)(n=6) * *$ \\
\hline
\end{tabular}

Values are given as means (SD); A, 11-dehydrocorticosterone; B, corticosterone; numbers of animals are given in parentheses. $11 \beta \mathrm{HSD}$ activity is given in

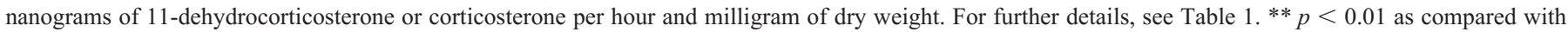
the controls.

by following the changes of sucrase, alkaline phosphatase, and $\mathrm{Na}, \mathrm{K}-\mathrm{ATPase}$ activities (Table 3). Sucrase activity increased between days 18 and 24 of age, and this increase was more obvious in the jejunum than in the ileum. This normal weaning-associated maturational increase in sucrase was not influenced by administration of CBX. Alkaline phosphatase activity was higher in the jejunum than in the ileum and colon and remained unchanged during CBX treatment. Na,K-ATPase activity was enhanced during weaning in all investigated segments, and this pattern was not influenced by CBX in the small intestine. In contrast, the activity of colonic $\mathrm{Na}, \mathrm{K}$-ATPase was greater in CBX-treated pups than in control animals.

Serum corticosterone concentration and $11 \beta \mathrm{HSD}$ activity in $\boldsymbol{C B X}$-treated rats. Finally, we examined serum corticosterone concentrations and $11 \beta \mathrm{HSD}$ in the liver and kidney, i.e. in tissues with high activity of $11 \beta \mathrm{HSD}$. CBX treatment significantly increased the serum concentrations of corticosterone; in control rats, the concentration was $98 \mathrm{ng} / \mathrm{mL}$ (39 ng/mL; $n=$ 11), whereas in CBX-treated animals, it was three times higher [294 ng/mL $(123 \mathrm{ng} / \mathrm{mL}) ; n=15, p<0.01]$. Activity of $11 \beta \mathrm{HSD}$ in renal and hepatic tissue is shown in Table 4. In vivo administration of CBX inhibited both $11 \beta$-dehydrogenase and 11-reductase activity (assayed ex vivo) in the liver and the former activity in the kidney. These data demonstrate that the administration of CBX administered in vivo inhibits both isoforms of $11 \beta \mathrm{HSD}$.

\section{DISCUSSION}

Our data have indicated that $\mathrm{CBX}$ influences the postnatal development of the intestine by modulating corticosterone metabolism. This conclusion is supported by two experimental findings. First, CBX administration markedly stimulated serum concentrations of corticosterone. Second, CBX suppressed the in vivo activity of $11 \beta \mathrm{HSD}$ in the kidney, liver, and probably also in other peripheral tissues. Thus, the increased serum corticosterone concentrations in young rats may be explained by inhibition of $11 \beta \mathrm{HSD}$, similarly as was shown in adult rats $(16,24,25)$. Furthermore, besides a systemic effect of CBX, the local effect of the drug on intestinal $11 \beta \mathrm{HSD}$ cannot be excluded. Suckling rats express intestinal 11-dehydrogenase but not 11-reductase activity, and this dehydrogenase activity is relatively high in the colon, small in the ileum, and absent in the jejunum (3). It thus cannot be excluded that CBX also exerted a direct effect on colonic but not on small intestinal development by inhibiting colonic $11 \beta \mathrm{HSD}$. Even if CBX had been shown to inhibit not only $11 \beta$ HSD but also several other short-chain alcohol dehydrogenases, particularly prostaglandin dehydrogenases (26), this effect is very unlikely to have occurred in our experiments. The concentration of CBX required for inhibition of prostaglandin dehydrogenases is much higher than the nanomolar $\mathrm{K}_{\mathrm{i}}$ for $11 \beta \mathrm{HSD}$, and CBX exhibits high nonspecific binding to plasma and cellular proteins (2, 27-29). In addition, the effect of CBX on morphologic and enzymatic development was different from that of prostaglandin administration in suckling rats $(30,31)$.

Our data provide evidence for the effect of CBX on enterocyte maturation and intestinal growth. Whereas intestinal growth was accelerated by CBX both in the small intestine and in the colon, the enzyme activities were not influenced, with the exception of colonic Na,K-ATPase, on day 18 or 24 . The finding that enzyme activities of 18- and 24-d-old CBX-treated pups did not significantly differ from those of vehicle-injected animals indicates that CBX possibly accelerated enzyme development at earlier stages of life and that the effect of acceleration of enzyme maturation disappeared before the pups reached the 18th day of life. Data supporting this conclusion have recently been published by Nanthakumar and Henning (32) and Beckett et al. (33) for the glucocorticoid induction of sucrase. In contrast to sucrase and alkaline phosphatase, CBX stimulated Na,K-ATPase activity in the colon but not in the small intestine, even though glucocorticoids have been shown to stimulate this enzyme activity in both the small and large intestines (13-15). Two possibilities may account for this discrepancy. First, the glucocorticoid sensitivity of the colon was higher than that of the small intestine. Second, perhaps a more likely explanation concerns that CBX administration inhibits colonic $11 \beta \mathrm{HSD}$ and that the impaired corticosterone metabolism results in glucocorticoid induction of $\mathrm{Na}, \mathrm{K}$-ATPase via mineralocorticoid receptors $(4,34,35)$. Additional studies are warranted to examine the small and large intestinal response of $\mathrm{Na}, \mathrm{K}-\mathrm{ATPa}$ e to CBX.

Our results support the anabolic effect of physiologic glucocorticoids on intestinal growth in suckling and weanling rats and the inhibitory effect of peripheral glucocorticoid metabolism on this process. A beneficial effect of glucocorticoids on intestinal growth and on villus height and crypt depth was observed in suckling and weanling mammals of various species $(7,8,36)$, including organ culture of suckling rat jejunum (37). In contrast, adrenalectomy (38) or administration of glucocorticoid antagonists (9) retarded both the growth and the increase of crypt depth and villus height, which are typical for the weaning period (6). The mucosa of suckling pups treated with CBX had a higher DNA and protein content per centimeter as well as higher villus height and/or crypt depth compared with control animals, but there were no differences in protein/DNA ratio, a commonly used measure of cell 
size. These changes may be due to increased DNA synthesis and accelerated rate of cell turnover (39).

\section{CONCLUSION}

In conclusion, we have demonstrated that the in vivo inhibition of $11 \beta \mathrm{HSD}$ in suckling and weanling rats results in significant alterations of certain aspects of intestinal growth and maturation. The findings that CBX increases plasma concentration of corticosterone and influences growth of intestinal segments with low or negligible activity of $11 \beta$ HSD could be taken as evidence that in vivo CBX does not act directly on the intestine but rather via changes of corticosterone levels. However, stimulation of $\mathrm{Na}, \mathrm{K}-\mathrm{ATPase}$ activity in the colon, which exhibits high $11 \beta \mathrm{HSD}$ activity, but not in the small intestine, where $11 \beta \mathrm{HSD}$ activity is low or absent (3), suggests that CBX might also be able to influence the effect of glucocorticoids directly in the target tissue.

Acknowledgments. We thank Mrs. I. Mezteková and R. Somolová for technical assistance, Dr. I. Mikšík for HPLC analysis, and Drs. J. Zicha and J. Vorlíček for valuable comments and reading the manuscript.

\section{REFERENCES}

1. Henning SJ, Rubin DC, Shulman RJ 1994 Ontogeny of intestinal mucosa. In: Johnson LR (ed) Physiology of the Gastrointestinal Tract. Raven Press, New York, pp 571-610

2. Stewart PM, Krozowski ZS 1999 11ß-hydroxysteroid dehydrogenase. Vitam Horm 57:249-324

3. Pácha J, Mikšík I 1996 11 $\beta$-hydroxysteroid dehydrogenase in developing rat intestine. J Endocrinol 148:561-566

4. Sheppard KE 1998 Decreased apparent affinity of corticosterone for colonic crypt glucocorticoid receptors is dependent on the cellular milieu and is distinct from corticosterone metabolism. J Steroid Biochem Mol Biol 64:35-42

5. Pácha J 2000 Development of intestinal transport function in mammals. Physiol Rev 80:1633-1667

6. Klein RM 1989 Small intestinal cell proliferation during development. In: Lebenthal E (ed) Human Gastrointestinal Development. Raven Press, New York, pp 367-392

7. Herbst JJ, Sunshine P 1969 Postnatal development of the small intestine of the rat Pediatr Res 3:27-33

8. Yeh K-Y, Yeh M, Holt PR 1987 Hormonal regulation of adaptive intestinal growth in artificially reared rat pups. Am J Physiol 253:G802-G808

9. Wu G, Flynn NE, Knabe DA, Jaeger LA 2000 A cortisol surge mediates the enhanced polyamine synthesis in porcine enterocytes during weaning. Am J Physiol 279:R554R559

10. Yeh K-Y, Yeh M, Montgomery RK, Grand RJ, Holt PR 1991 Cortisone and thyroxine modulate intestinal lactase and sucrase mRNA levels and activities in the suckling rat. Biochem Biophys Res Commun 180:174-1800

11. Nanthakumar NN, Henning SJ 1993 Ontogeny of sucrase-isomaltase gene expression in rat intestine: responsiveness to glucocorticoids. Am J Physiol 264:G306-G311

12. Uezato T, Fujita M 1983 Developmental transition of alkaline phosphatase from suckling to adult type in rat small intestine: molecular species and effect of injected cortisone and thyroxine. J Biochem 94:1483-1488

13. Fuller PJ, Verity K 1990 Colonic sodium-potassium adenosine triphosphate subunit gene expression: ontogeny and regulation by adrenocortical steroids. Endocrinology $127: 32-38$
14. Zemelman BV, Walker WA, Chu SW 1992 Expression and developmental regulation of $\mathrm{Na}^{+}, \mathrm{K}^{+}$adenosine triphosphatase in the rat small intestine. J Clin Invest 90:10161022

15. Zemanová Z, Pácha J 1998 Localization of Na,K-ATPase activity in developing rat distal colon: role of corticosteroids. Mech Ageing Dev 101:129-143

16. Whorwood CB, Sheppard MC, Stewart PM 1993 Licorice inhibits $11 \beta$ hydroxysteroid dehydrogenase messenger ribonucleic acid levels and potentiates glucocorticoid hormone action. Endocrinology 132:2287-2292

17. Walker BR, Connacher AA, Lindsay RM, Webb DJ, Edwards CRW 1995 Carbenoxolone increases hepatic insulin sensitivity in man: a novel role for 11-oxosteroid reductase in enhancing glucocorticoid receptor activation. J Clin Endocrinol Metab $80: 3155-3159$

18. Albiston AL, Obeyesekere VR, Smith RE, Krozowski ZS 1994 Cloning and tissue distribution of the human $11 \beta$-hydroxysteroid dehydrogenase type 2 enzyme. Mol Cell Endocrinol 105:R11-R17

19. Henning SJ, Guerin DM 1981 Role of diet in the determination of jejunal sucrase activity in the weanling rat. Pediatr Res 15:1068-1072

20. Murer H, Amman E, Biber J, Hopfer U 1976 The surface membrane of the small intestinal epithelial cell. I. Localization of adenyl cyclase. Biochim Biophys Acta 433:509-519

21. Pácha J, Teisinger J, Popp M, Čapek K 1991 Na,K-ATPase and the development of $\mathrm{Na}^{+}$transport in rat distal colon. J Membr Biol 120:201-210

22. Bradford MM 1976 A rapid and sensitive method for the quantitation of microgram quantities of protein utilizing the principle of protein-dye binding. Anal Biochem $72: 248-254$

23. Giles KW, Myers A 1965 An improved diphenylamine method for the estimation of deoxyribonucleic acid. Nature 206:93

24. Horigome H, Horigome A, Homma M, Hirano T, Oka K 1999 Glycyrrhetinic acid-induced apoptosis in thymocytes: impact of $11 \beta$-hydroxysteroid dehydrogenase inhibition. Am J Physiol 277:E624-E630

25. Sewell KJ, Shirley DG, Michael AE, Thompson A, Norgate DP, Unwin RJ 1998 Inhibition of renal $11 \beta$-hydroxysteroid dehydrogenase in vivo by carbenoxolone in the rat and its relationship to sodium excretion. Clin Sci 95:435-443

26. Baker ME, Fanestil DD 1991 Licorice, computer-based analyses of dehydrogenase sequences, and the regulation of steroid and prostaglandin action. Mol Cell Endocrinol 78:C99-C102

27. Monder C 1991 Corticosteroids, kidneys, sweet roots and dirty drugs. Mol Cell Endocrinol 78:C95-C98

28. Michael AE, Thompson A, Norgate DP, Sewell KJ, Shirley DG, Unwin RJ 1996 Inhibition of renal prostaglandin $(\mathrm{PG})$ and glucocorticoid inactivation by carbenoxolone: relationship to renal sodium excretion. J Am Soc Nephrol 7:1649

29. Teelucksingh S, Benediktsson R, Lindsay RS, Burt D, Seckl JR, Edwards CRW, Nan CL, Kelly R 1991 Liquorice. Lancet 337:1549

30. Koelz HR, Lentze MJ, Müller OM, Halter F 1987 Effect of 16,16-dimethyl prostaglandin $E_{2}$ on small intestinal mucosa in suckling rats. Eur J Clin Invest 17:293-300

31. Marti A, Fernandez-Otero MP 1994 Prostaglandin $E_{2}$ accelerates enzymatic and morphological maturation of the small intestine in suckling rats. Biol Neonate 65:119-125

32. Nanthakumar NN, Henning SJ 1993 Ontogeny of sucrase-isomaltase gene expression in rat intestine: responsiveness to glucocorticoids. Am J Physiol 264:G306-G311

33. Beckett PR, Fiorotto ML, Davis TA, Reeds PJ 1996 Corticosterone has independent effects on tissue maturation and growth in the suckling rat. Pediatr Res 39:395-400

34. Whorwood CB, Ricketts ML, Stewart PM 1994 Regulation of sodium-potassium adenosine triphosphate subunit gene expression by corticosteroids and $11 \beta$ hydroxysteroid dehydrogenase activity. Endocrinology 135:901-910

35. Tsuganezawa H, Hayashi M, Fujii Y, Yamaji Y, Iyori M, Saruta T 1995 Corticosterone increases $\mathrm{Na}^{+}-\mathrm{K}^{+}$-ATPase activity in rat cortical collecting ducts with inhibition of 11 $\beta$-hydroxysteroid dehydrogenase. Renal Physiol Biochem 18:66-72

36. Chapple R, Cuaron JP, Easter RA 1989 Effect of glucocorticoids and limited nursing on the carbohydrate digestive capacity and growth rate of piglets. J Anim Sci 67:2956-2973

37. Albert V, Barkla D, Young GP 1994 Serum-free organ culture of suckling rat jejunum: effect of regulatory hormones. In Vitro Cell Dev Biol Anim A 30:443-449

38. Yeh K-Y, Moog F 1977 Influence of the thyroid and adrenal glands on the growth of the intestine of the suckling rat and on the development of intestinal alkaline phosphatase and disaccharidase activity. J Exp Zool 299:337-348

39. Neu J, Crim WN, Hodge NC 1986 Comparative effects of glucocorticoids and prostaglandins on small intestine of infant rats. Pediatr Res 20:109-112 